\title{
Blockchain Quarantine Monitoring System for the Control of Covid-19 Pandemic
}

\author{
Siddika Ersoy \\ Suleyman Demirel University, Faculty of Health Science, \\ Department of Nursing, Division of Medical Nursing, Isparta, Turkey \\ E-mail: siddikaersoy@gmail.com \\ Remzi Gurfidan \\ Isparta University of Applied Sciences, Yalvac Vocational School of Technical Sciences, \\ Department of Computer Programming, Isparta, Turkey \\ Rukiye Pinar Boluktas \\ Istanbul Sabahattin Zaim University, Faculty of Health Sciences, \\ Department of Nursing, Istanbul, Turkey \\ Sukran Ozkahraman Koc (Corresponding author) \\ Suleyman Demirel University, Faculty of Health Science, \\ Department of Midwifery, 32260, Cunur/Isparta, Turkey \\ E-mail: sukran.ozkahraman@gmail.com
}

\begin{abstract}
Objective: After the emergence of the new type of coronavirus (COVID-19) as a viral respiratory disease, it has started to increase rapidly and steadily all over the world. Several studies are carried out in different areas all over the world in order to control and effectively treat the disease. However, it seems that the most appropriate way to manage the pandemic is to prevent the transmission. In many different countries and Turkey the spread of the covid-19 pandemic is being taken under control with innovative digital tecnologies. In this study, we tested whether the blockchain application can be used in the successful execution of quarantine processes in order to support the controlled progress of the COVID-19 pandemic process. Method: In this study, a unique control system called Blockchain Quarantine Monitoring System is proposed to monitor a quarantined closed area. The study is based on the problem scenario related to the isolation of the predicted quarantine patient. Results: The proposed model started with placing a quarantine control system at the entrance of the closed area where quarantine is applied. As the last step, the Quarantine Monitoring System web software was developed so that the quarantine monitoring system can work in all areas where the internet is available, regardless of location. Conclusions: The modeling suggested in our study showed that; Block chain application is a useful method for the effectiveness of quarantine, which is the main factor that can reduce the spread of pandemics.
\end{abstract}

Keywords: COVID-19, blockchain, pandemic, quarantine.

Special Issue of Health Sciences

DOI: $10.7176 / \mathrm{JSTR} / 7-08-01$

\section{Introduction}

The new coronavirus disease (COVID-19) first emerged on January 13, 2020 in Wuhan, China, as a new viral respiratory tract disease defined by high fever and shortness of breath. It was declared a pandemic by the World Health Organization (WHO), as it steadily began to emerge among the masses in different parts of the world. According to WHO, 3,025,835 people have died due to COVID-19 in 223 countries as of 20 April 2021 (1). 
Due to nature of COVID-19 being highly contagious, lack of effective antiviral treatment, and a mortality rate of more than $1 \%$, it is seen that the only way to manage COVID-19 pandemic is to prevent its transmission. However, statistics reveal that the success of countries in managing COVID19 varies from each other (1).

The first COVID-19 case in Turkey was seen on 11 March 2020, and the first wave was successfully managed in a period of approximately 3 months until the end of May as a result of measures, such as introduction of distance education in schools, transition to remote working system in some of the workplaces, closure of entertainment venues such as hairdressers, nightclubs, bars, discos, implementation of a partial curfew, travel ban, distributing free masks to individuals in the risk group, and strict supervision of law through enforcement officers. During this period, symptomatic patients diagnosed with COVID-19 were hospitalized and treated, and individuals with a positive PCR test result without symptoms and those who were in contact with COVID-19 patients were isolated and quarantine at home for 2 weeks and followed up. However, as the pandemic prolonged, the so-called "new normal" period started as of 1 June 2020, mainly due to economic reasons, travel restrictions were lifted during this period, and there was a return to social life with recommendations, such as social distancing rule and individual precautions (2). With these new normal period practices, despite all the efforts of the Ministry of Health and relevant institutions, serious difficulties have been experienced regarding compliance with individual protective measures and quarantine and isolation measures. It was determined that the cases tested positive, who were diagnosed at different times and who had decided to continue their treatment at home, taking into account the suitability of their conditions, entered public environments during the quarantine period and even continued to work (3-5). According to the news in the media, it was observed that most cases occurred after attending events, such as weddings and funerals, even though being aware that they were tested positive, they were within these organizations. For example, according to the news of Bursa Yeni Dönem Newspaper dated 10 August 2020, a woman attending her daughter's wedding, although she knew that she was COVID19 positive, hid this situation from the guests by saying, "If my illness is known, nobody will come to the wedding," but after a while, most of the guests who attended the wedding were hospitalized due to symptoms and it was found that they were infected with COVID-19 (6). As a result of a person with COVID-19 attending a wedding in Malatya, 19 people (7) were infected after the wedding in Devrek District of Zonguldak Province (8). Again, after mass participation in funerals, COVID-19 was detected in a significant number of individuals. For example, in the village of Taşkınpaşa, which was quarantined 8 days prior to that day in the Ürgüp district of Nevşehir, 45 people were tested positive for COVID-19 after collective funeral prayers (9).

In order to control and supervise cases that need to be isolated, filiation teams were established by the Ministry of Health in July 2020 (2); however, the desired success in providing adequate control could not be achieved. On evaluation of all these events, it can be concluded that despite the efforts of the relevant institutions and organizations, especially the Ministry of Health in our country, the society did not adequately comply with the isolation and quarantine measures. The repercussions of this situation were clearly seen with the increasing number of cases in the autumn and subsequent winter months. According to the data of Hayat Eve Sığar/Life Fits into Home (HEPP) application dated 20 April 2021, the total number of cases in Turkey reached 4,384,624 and the number of deaths reached 36,613.

It is possible to find similar examples in other countries, although they are not as common as in Turkey. In America and Canada, for example, it was observed that protesters who took to the streets by not accepting the protective measures taken by governments did not pay attention to any protective measures, such as social distancing and masks (10).

\section{Digital Technologies and COVID-19}

The IT sector is developing day by day and offers innovative solutions for different measurement parameters, such as performance, cost, and security. These innovations are followed with interest by all academic fields and adapted by various fields. The field of health, which is directly related to human health among the different adapted fields, stands out from other fields. The digital technologies that we see being used in the field of health can be summarized as the next generation network "internet of things-IoT" (eg. 5G) (11), big data analytics (for example, the E-government application) (12), artificial intelligence using deep learning (13) and blockchain technology (14). In recent years, studies have been conducted on imaging devices, surgical robots, and artificial intelligence-based decision support systems (15-16).

With the emergence of COVID-19 pandemic, the use of digital technologies has gained momentum in several areas from education to management to health. Various countries around the world are trying to confront the COVID-19 pandemic by taking advantage of the possibilities of digital technology and to

2 | P a g e www.iiste.org 
control the spread of COVID-19 with community-driven, communication-tracking technologies. For example, in the follow-up of COVID-19, IoT provides a platform that allows public health institutions to access data. The 'Worldometer' application provides real-time data such as the total number of cases, new cases, serious cases, recovered cases, the number of patients who died, on a daily basis, both globally and on a country basis (17). John Hopkins University Center for Systems Science and Engineering created a real-time monitoring map using data collected from the US Centers for Disease Control and Prevention (CDC), the WHO, the European Center for Disease Prevention and Control, the China Center for Disease Prevention and Control (18). It is possible to multiply similar examples.

In this process, we witness the increasing use of new generation technologies and the investments made in Turkey. Education Informatics Network (EBA), which allows students to continue their education through digital channels, the "Online Corona Prevention» website, which works with the machine learning algorithm published by the Ministry of Health, the "Corona Tracking" program developed by Boni Global, a Turkish R\&D company, which is used to monitor and record interactions between users and notifies all other users who were in contact with the infected user if a user is reported to be exposed to the virus, and finally the "Life Fit into Home" application, which provides digital monitoring of patients who need to be isolated at home with the cooperation of three major mobile operators and the Information Technologies and Communication Authority, also known as BTK, are the examples of the work carried out in Turkey within the scope of combating COVID-19. (19).

One of the increasingly used digital technologies in the world is the blockchain application (20). In this study, we tested whether the blockchain application can be used in the successful execution of quarantine processes in order to support the controlled progress of the COVID-19 pandemic process. In the following section, the blockchain application will be briefly described, the studies carried out by using blockchain will be discussed, and information on our own work will be included.

\subsection{Blockchain Technology}

Blockchain technology is one of the most interesting technologies of the recent period in terms of network structure, architecture, and system algorithm. A blockchain, which has a structure consisting of blocks, can be defined as a distributed database system that provides encrypted transaction tracking. Each transaction made in the next generation transaction verification mechanism running in a distributed structure and recorded encrypted is transformed into a "block" structure and associated with the block before it. Each block is recorded by adding it to the last block in the existing chain and following each other. The blocks are encrypted during the transactions, they are made tamper-proof and unbreakable. In summary, when a transaction is approved in the system and added to the chain, it becomes impossible to change (21-22). The basic structure of the blockchain is shown in Figure 1.

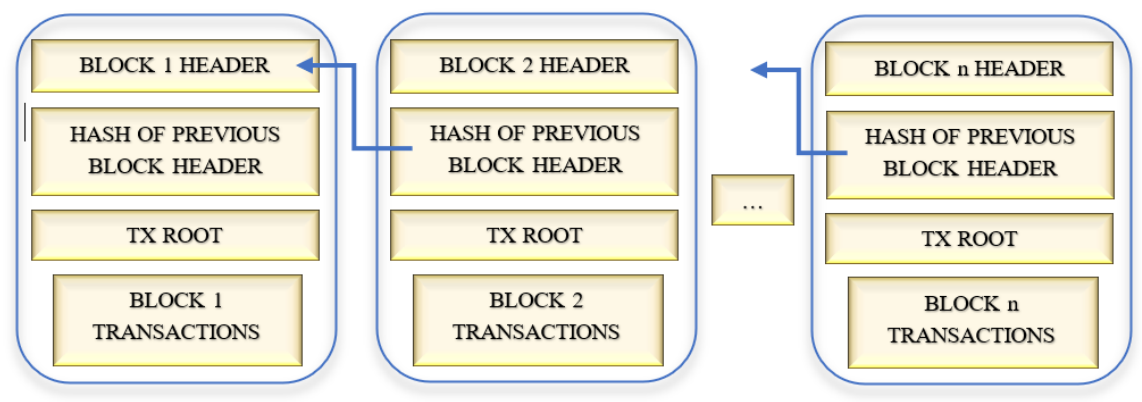

Figure 1. Blockchain Basic Structure

A blockchain includes all transactions made between stakeholders who are the participants of the system, each transaction agreed upon is converted into smart contracts, and accepted by all stakeholders of the system. In summary, the blockchain core ensures that the entire transfer path of an object is fully recorded and traced. Therefore, blockchain is one of the most interesting technologies that can be used to protect business processes from both errors and illegal activities, such as fraud, and independently verify all kinds of critical information (23). The use of blockchain technology is becoming increasingly widespread, especially in the field of health, where data security and privacy are very sensitive. It stands out as a popular method in ensuring the security of medical images in the health sector (24-25). 


\subsection{Studies on Blockchain}

There are studies on the detection of objects and people for different purposes with the camera using image processing technology. For example, Munoz-Salinas et al. (26) presented a system that can detect and monitor more than one person. In the design of the system, the cameras are placed in a position under the head. The images taken are processed in real-time and modeled on the computer. It is thought that the human head has an average size for face detection. The system analyzes whether the points on the top of the object show a width similar to the width of the human head.

Haritaoglu et al. (27) conducted a study on determining human body parts and posture positions using similar techniques. Snidaro and Micheloni (28) worked on video footage for media intelligence. For this purpose, they placed fixed cameras at different points of the environment and analyzed the images they obtained by converting them to black and white format. Soo (29) conducted studies on object detection using the Haar-cascade classifier, which is a method used to find an object on the image. In the study, an edge feature, a line feature, and a four-rectangle feature, found in the Haar-cascade, were used. Padilla (30), Kasinki and Schmidt (31), Setjo et al. (32) studied the detection of human faces and human eyes on the image using the Haar-cascade classifiers.

In the current study, the Viola-Jones algorithm was used by making use of the Haar-cascade classifier features in order to determine the features sought in the image, unlike the aforementioned studies. The images obtained were converted to Base64 format, converted to character expressions, and then transformed into a blockchain structure to ensure their security.

\subsection{Blockchain Quarantine Monitoring System}

In this study, a unique control system called Blockchain Quarantine Monitoring System is proposed to monitor a quarantined closed area. The problem scenario envisaged in the study is based on the necessity of complying with the ban on visitors in a closed area with quarantine patients or patients with COVID-19. The purpose of quarantine practices is to isolate individuals in the quarantine area, thus preventing the spread of disease. However, as witnessed during the pandemic process, COVID-19 positive individuals can break the rules and do not fulfill the quarantine requirements during this vital period. For example, a Pandemic Tracking System was established in order to monitor individuals under quarantine in our country, and a warning message was sent to their mobile phones when COVID19 positive individuals left their residences. Despite this, a significant number of people have violated quarantine rules by leaving their mobile phones at home. The proposed blockchain application is capable of eliminating all these risks. The system architecture of the proposed model is shown in Figure 2.

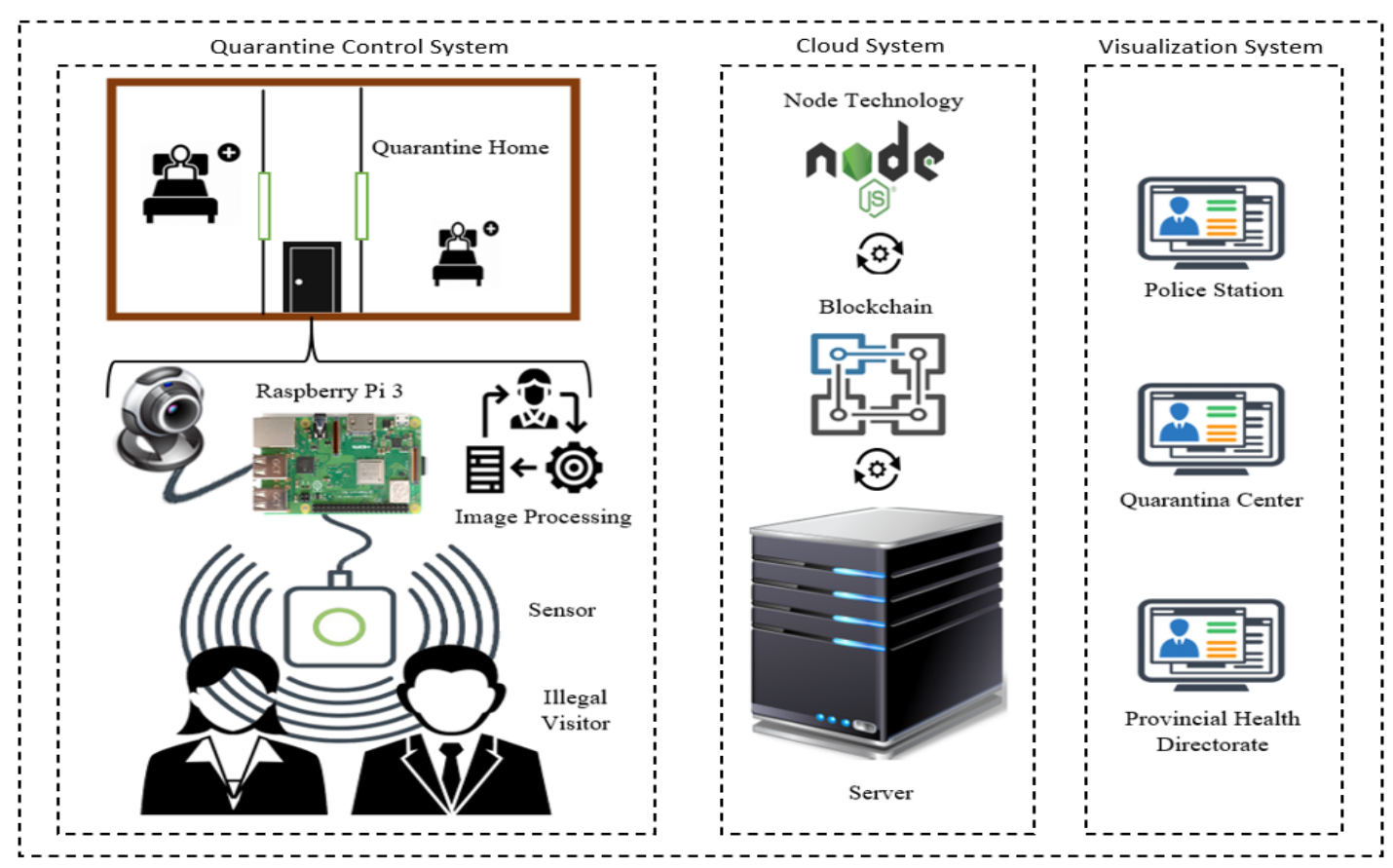

Figure 2. Architecture of the Proposed Model 
The proposed model starts with the placement of a quarantine control system at the closed area entrance where quarantine is applied (for example, at the entrance of an apartment). The quarantine control system includes a camera and a motion sensor connected to the Raspberry Pi 3 device. As soon as a motion is detected at a distance closer to the specified distance to the quarantine area, the Raspberry Pi 3 is informed by the motion sensor. As soon as the Raspberry Pi 3 receives a signal from the motion sensor, it takes a photo of the area using the camera connected to it. The source of the movement can have different reasons. It applies image processing algorithms on the image it obtains to detect the presence of a person at an illegal distance to the quarantine zone. Image processing algorithms written in Python language in Raspberry Pi 3 are programmed to detect human face and human eye. When people wear a mask, the face detection algorithm may not work properly. This problem can be eliminated by eye detection algorithms. Sample pictures in which face and eye detection algorithms were applied are shown in Figure 3.

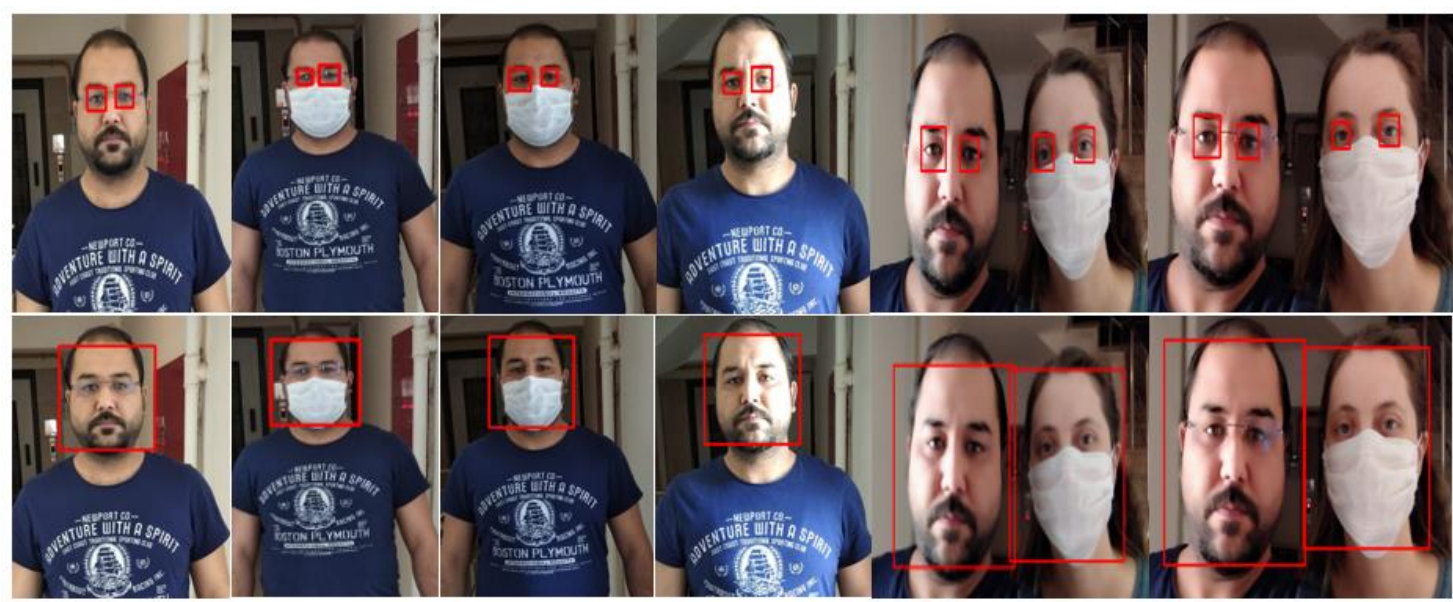

Figure 3. Face and Eye Algorithm Applied to Sample Photographs

As soon as the person is detected on the processed image, the Raspberry Pi 3 device converts the original image into Base64 format and sends it to the server. The data received with the blockchain software prepared in the server is transformed into a blockchain structure on the server. Blockchain technology is preferred because it minimizes the risk of images being stolen, deleted, altered, or tampered. Image data in Base64 format converted into blockchain structure is stored on the server. In addition, the Node.js environment based on the principle of asynchronous operation is installed on the server.

As soon as new information is added to the blockchain structure installed on the server, a notification message is sent to the quarantine monitoring stations established in different regions. The content of the message to be sent also includes the original image obtained. The image converted in Base64 format is decoded on the server and converted to image format. The content of the message includes the address where the quarantine control system is installed, the original image of illegal visitor, and the time stamp. At the same time, in the Quarantine Monitoring System, the addresses where the quarantine control system is installed and information about the quarantine period can be displayed.

\subsection{Image Processing Method}

The study conducted by Viola and Jones (33) is known as the first robust and real-time face detection detector, which is still valid today. The most important reason for the success of this sensor is the integral image, Adaboost and cascade structure. An integral image is the algorithm that gives the sum of density values in a rectangular subset within the resulting image. Formula 1 is used to calculate the integral image (34). The value held by $(x, y)$ in formula 1 is the density of the grayscale image in the pixel $(\mathrm{x}, \mathrm{y})$.

$$
i i(x, y)=\sum_{\substack{x^{\prime}<x \\ y^{\prime}<y}} i\left(x^{\prime}, y^{\prime}\right)
$$


Using the integral image, the sum of the density pixels of the ABCD rectangular area named by any points $\mathrm{A}, \mathrm{B}, \mathrm{C}, \mathrm{D}$ on the image can be calculated by formula 2, taking into account only the four string references.

$$
\sum_{(x, y) \in A B C D} i(x, y)=i i(D)+i i(A)-i i(B)-i i(C)
$$

Viola and Jones used it for the quick calculation of numerous Haar-like features defined as the difference between the sum of densities in the dark-shaded and light-shaded regions of simple rectangular patterns as shown in Figure 4 (33-34).

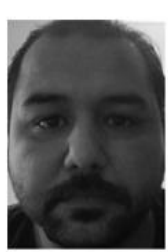

(a)

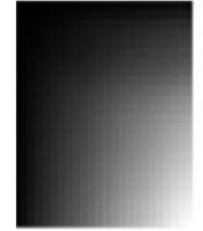

(b)

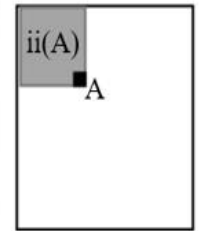

(c)

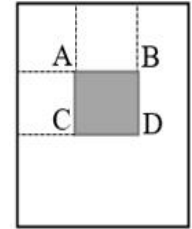

(d)

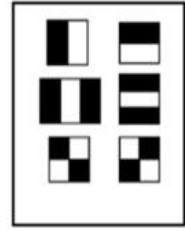

(e)

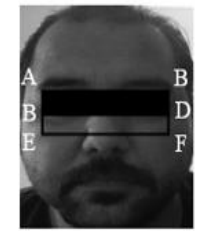

(f)

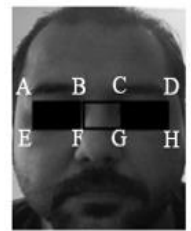

(g)

Figure 4. Effective Calculation of Haar-Like Feature Using Integral Image

(a) Original image, (b) Integral image, (c) Illustration of $i i(A)$, (d) Illustration of equation 2, (e) Examples of Haar-like features, (f) Example of a Haar feature overlapped with original image and illustration of equation 3, (g) Example of another Haar feature overlapped with original image.

Formula 3 is used for the calculation of the image sample shown in Figure 3.

$$
f=[i(D)+i i(A)-i i(B)-i i(C)]-[i(F)+i i(C)-i i(D)-i i(E)]
$$

\subsection{Blockchain method}

In order to ensure the security of the data obtained in the system, the data obtained from the quarantine control system are stored in the blockchain structure. This software that we have created is used to transform the data coming to the server into a blockchain structure. The working algorithm of the software is shown in Algorithm 1.

Algorithm 1: Creating a hash for Base 64 format Image

Input: DeviceId, Received information, Timestamp, Previous hash

Output: Currenthash

1 Extract image data from incoming data

2 Convert Base64 format data to image format

3 Combine the incoming data with the hash of the previous data

4 Apply Hash algorithm to the final data

5 Send the obtained data to quarantine tracking stations

The device number of the quarantine control system (also showing the address information), the picture taken by the system, the time stamp, and the hash information of the previous information are provided as input data to the software. When the software is executed, a hash containing new information is generated as output. 


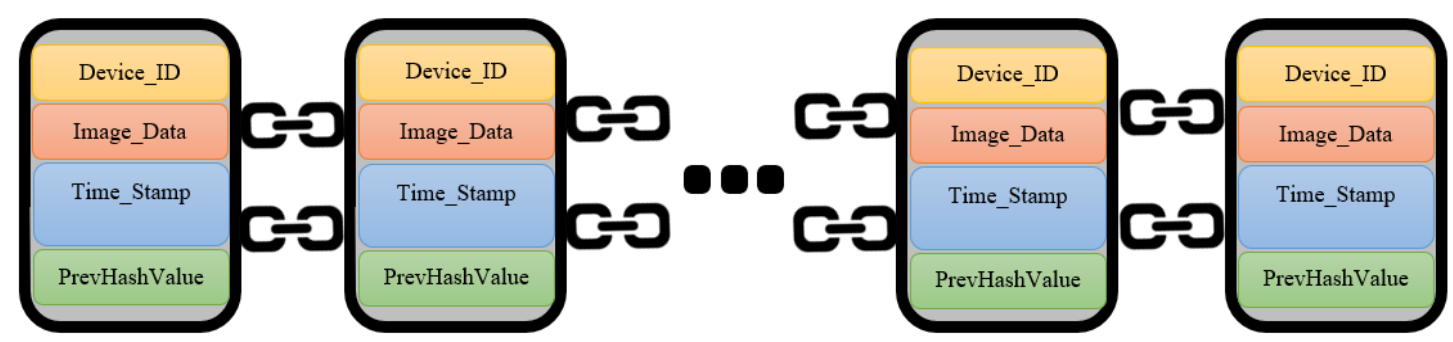

Figure 5. Blockchain Structure Created on Server

The structure of storing the data obtained from the quarantine control system on the server is shown in Figure 5. In accordance with the basic structure of the blockchain, each data is stored after it is combined with the hash information of the data that comes before it and subjected to the hash algorithm again.

\subsection{Quarantine Monitoring System}

The Quarantine Monitoring System, which we can say is the final layer of the proposed model, has been implemented as web software. In this way, the Quarantine Monitoring System can work in all areas where the internet is available, regardless of location. Node.js technology, which works with asynchronous demand fulfillment logic, was used in the realization of the software. The Quarantine Monitoring System implemented is shown in Figure 6.

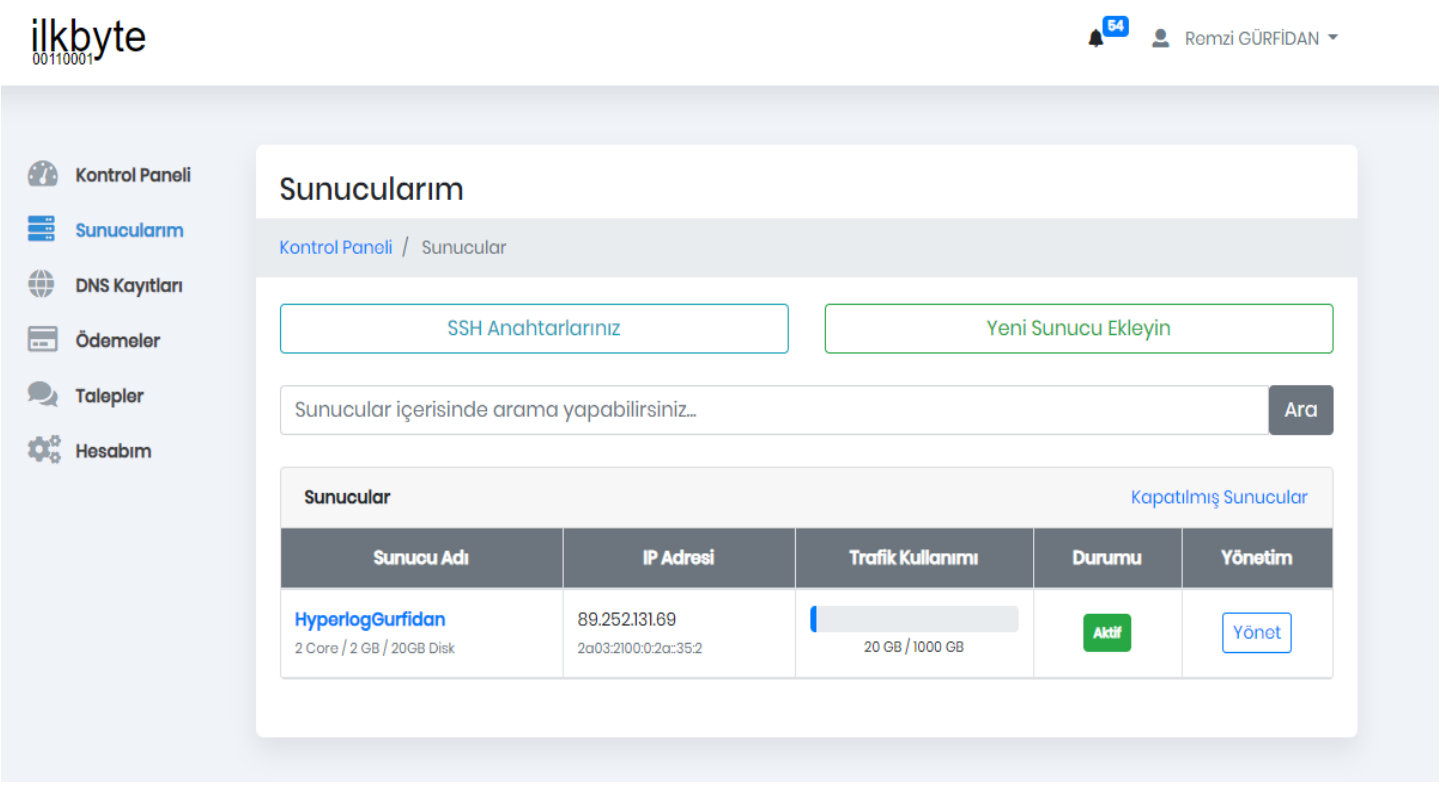

Figure 6. Quarantine Monitoring System

The Quarantine Monitoring System displays the addresses where quarantine control systems are installed, the remaining quarantine periods of the quarantine zones, if illegal visitors are detected, pictures of the illegal visitors, and information on time of the visit.

\section{Conclusion}

During the COVID-19 pandemic, when the total number of cases exceeded 143 million in 223 countries and the number of deaths reached 3,056,400 (17), after analyzing the results of our study we think that the blockchain application was an effective method to support the measures carried out by the authorized institutions to control the increasing transmission of the COVID-19 disease. 


\section{References}

1. World Health Organisation. (2020, December 10). Coronavirus disease (COVID-19) pandemic. https://www.who.int/emergencies/diseases/novel-coronavirus-2019

2. BBC News. (2020, Haziran 3). Koronavirüs: Adım adım Türkiye'nin Covid-19'la mücadelesi. https://www.bbc.com/turkce/haberler-turkiye-52899914. Erişim Tarihi; 10.12.2020

3. TRT Haber. (2020, Eylül 10). https://www.trthaber.com/haber/turkiye/karantinada-olmasigerekirken-cay-ocaginda-calisan-kisiye-ceza-515333.html Erişim Tarihi; 10.12.2020

4. Sözcü. (2020, Ağustos 28). https://www.sozcu.com.tr/2020/gundem/yok-artik-dedirtecek-olaykarantinada-olmasi-gerekirken-valilige-gitti-6000987/ Erişim Tarihi; 10.12.2020

5. Milliyet. (2020, Eylül 12). https://www.milliyet.com.tr/gundem/samsunda-salgin-tedbiriihlallerine-ihbar-yagmuru-6304614 Erişim Tarihi; 12.12.2020

6. Yeni Dönem Gazetesi. (2020, Ağustos 10). Bile bile virüs saçtı. https://www. Yeni donem .com.tr/yazarlar/lale-akasoy-61/bile-bile-virus-sacti-13701.html

7. CNN Türk. (2020, Temmuz, 17). https://www.cnnturk.com/turkiye/dugun-sonrasi-19-kisidekoronavirus-tespit-edildi.

8. Sözcü (2020, Temmuz, 20) https://www.sozcu.com.tr/2020/saglik/bir-dugun-yaptilar-coronasayisi-patladi-5941963/

9. Hürriyet. (2020, Nisan 29). https://www.hurriyet.com.tr/gundem/cenaze-namazina-katilan-45kisinin-corona-virusu-testi-pozitif-cikti-41506127

10. Wikipedia (2020, March 15). Protests over responses to the COVID-19 pandemic. https://en.wikipedia.org/wiki/Protests_over_responses_to_the_COVID-19_pandemic. Erişim Tarihi: 12.12 .2020

11. Ting DSW, Lin H, Ruamviboonsuk P, Wong TY, Sim DA. (2019). Artificial intelligence, the internet of things, and virtual clinics: ophthalmology at the digital translation forefront. Lancet Digital Health. 2019;2(1).

12. Shilo S, Rossman H, Segal E. Axes of a revolution: challenges and promises of big data in healthcare. Nat Med. 2020;26:29-38.

13. Ting DSW, Liu Y, Burlina $P$, Xu X, Bressler NM, Wong TY. AI for medical imaging goes deep. Nat Med. 2018;24:539-540.

14. Heaven D. (2019). Bitcoin for the biological literature. Nature, 01 Feb 2019, 566(7742):141142. https://www.nature.com/articles/d41586-019-00447-9

15. Akçay Z, Gürfidan R. Estimation of depression disease by neural fuzzy inference method. International Journal of Engineering and Innovative Research. 2018; 1(2), 49-58.

16. Hijazi S, Page A, Kantarci B, Soyata, T. Machine learning in cardiac health monitoring and decision support. Computer. 2016;49(11):38-48.

17. https://www.worldometers.info/coronavirus/. 12 Decenber 2020

18. https://gisanddata.maps.arcgis.com/apps/opsdashboard/index.html\#/bda 7594740fd40 2994234 67 b48e9ecf6/ 
19. Deloitte. Yeni nesil teknolojilerin COVID-19 mücadelesindeki önemi - Ülke Örnekleri. https://www2.deloitte.com/content/dam/Deloitte/tr/Documents/consulting/yeni-nesil-tekno loji lerin -covid-19-mucadelesindeki-onemi.pdf. Erişim Tarihi; 10.12.2020

20. Ting DSW, Carin L, Dzau V.et al. Digital technology and COVID-19. Nat Med. 2020;26: 459461 .

21. Nofer M, Gomber P, Hinz O, Schiereck D. Blockchain. Business \& Information Systems Engineering. 2017;59(3):183-187.

22. Drescher D. Blockchain basics (Vol. 276); Planning the Blockchain. Berkeley. 2017. [Internet]. CA: Apress, 223-233. eBook ISBN:978-1-4842-2604-9. DOI:10.1007/978-1-4842-2604-9

23. Wu J, Tran NK. Application of blockchain technology in sustainable energy systems: An overview. Sustainability. 2018;10(9):3067.

24. Patel V. A framework for secure and decentralized sharing of medical imaging data via blockchain consensus. Health informatics journal. 2019,25(4),1398-1411.

25. Shen M, Deng Y, Zhu L, Du X, Guizani N. Privacy-preserving image retrieval for medical iot systems: A blockchain-based approach. IEEE Network. 2019;33(5): 27-33.

26. Muñoz-Salinas R, Aguirre E, García-Silvente M. People detection and tracking using stereo vision and color. Image and Vision Computing. 2007;25(6): 995-1007.

27. Haritaoglu I, Beymer D, Flickner M. Ghost/sup 3D: detecting body posture and parts using stereo. In Workshop on Motion and Video Computing. Proceedings, IEEE. 2002;175-180.

28. Snidaro L, Micheloni C, Chiavedale C. Video security for ambient intelligence. IEEE Transactions on Systems, Man, and Cybernetics-Part A: Systems and Humans. 2004;35(1):133144.

29. Soo S. Object detection using Haar-cascade Classifier. Institute of Computer Science, University of Tartu. 2014;1-12.

30. Padilla R, Costa Filho CFF, Costa MGF. Evaluation of haar cascade classifiers designed for face detection. World Academy of Science, Engineering and Technology. 2012;64:362-365.

31. Kasinski A, Schmidt A. The architecture and performance of the face and Eyes detection system based on the Haar cascade classifiers. Pattern Analysis and Applications. 2010;13(2):197-211.

32. Setjo CH, Achmad B. Thermal image human detection using Haar-cascade classifier. In 2017 7th International Annual Engineering Seminar (InAES). 2017;1-6.

33. Viola, P, Jones, M. "Rapid object detection using a boosted cascade of simple features," Computer Vision and Pattern Recognition (CVPR), 2001 IEEE Conference on, June 2001, 1-9. https://www.cs.cmu.edu/ efros/courses/LBMV07/Papers/viola-cvpr-01.pdf

34. EL-Barkouky ARA. Mathematical modeling for partial object detection. Chepter 2; Modeling Faces for Detection,9-36. [master's thesis]. Electronic Theses And Dissertations; 2014. 